\title{
Cytological Characterization of Brazilian Green Dwarf Coconut (Cocos nucifera L.) via Meiosis and Conventional and Differential Karyotyping
}

\author{
Telma Nair Santana Pereira ${ }^{1 *}$, Monique Freitas Neto", \\ Margarete Magalhaes de Souza ${ }^{2}$, Ingrid Gaspar da Costa Geronimo", \\ Clausio Antônio Ferreira de Melo $^{2}$ and Messias Gonzaga Pereira ${ }^{1}$ \\ ${ }^{1}$ Universidade Estadual do Norte Fluminense, Centro de Ciências e Tecnologias Agropecuárias, Laboratório de \\ Melhoramento Genético Vegetal, Av. Alberto Lamego 2000, 28013-602, Campos dos Goytacazes, RJ, Brasil \\ ${ }^{2}$ Universidade Estadual de Santa Cruz, Departamento de Ciências Biológicas, Rodovia Ilheus-Itabuna, Km 16, \\ Salobrinho, 45662-900, Ilhéus-Ba, Brasil
}

Received May 6, 2016; accepted January 15, 2017

\begin{abstract}
Summary The objective of this study was to characterize the Brazilian green Dwarf coconut (Cocos nucifera L.) by meiotic analysis and by conventional and differential karyotyping (CMA/DAPI and telomeric FISH). Sixteen pairs of bivalent were observed in the meiosis, indicating that the species is diploid and has $2 n=2 x=32$ chromosomes. Some abnormalities were observed, such as asynchronous division and anaphase with converging fibers. The estimated recombination rate for this species was 17.04, equivalent to an average of 1.06 chiasmata per bivalent. The meiotic index was $79 \%$ and the pollen viability was $89.5 \%$, both values considered satisfactory. The conventional karyotyping validated the observed number of chromosomes in the meiosis, i.e., $2 n=32$ chromosomes. The length of chromosomes ranged from $5.57 \mu \mathrm{m}$ to $2.13 \mu \mathrm{m}$. The karyotype was considered asymmetric, with 11 metacentric and five submetacentric chromosomes pairs. The CMA/DAPI banding revealed terminal blocks in two chromosome pairs (one metacentric and one submetacentric), which was coincident with the nucleolus organizing region (NOR), and allowed the satellite characterization, which had $1.36 \mu \mathrm{m}$ (chromosome 4) and $0.85 \mu \mathrm{m}$ (chromosome 7). The telomeric FISH revealed signs only in the terminal region in all chromosomes, suggesting that this species has undergone no structural rearrangement of chromosomes during its evolution and that the telomeres of the coconut chromosomes are Arabidopsis type (TTTAGGG).
\end{abstract}

Key words Coconut, Chromosome, Telomeric FISH, DAPI/CMA, Meiosis.

The coconut (Cocos nucifera L.) is a tropical palm tree of great economic importance which is cultivated in several countries. The Cocos genus is mono specific with diploid number of chromosomes $(2 n=2 x=32)(\mathrm{Be}-$ nassi et al. 2007). The species is formed by two main groups, the Dwarf group and the Tall group (Purseglove 1972).

These two groups of coconut varieties have very distinct characteristics; the Tall coconut has a large size, reaching up to $30 \mathrm{~m}$ high, is allogamous and has medium to large sized fruits, while the Dwarf coconut has smaller height, reaching up to $12 \mathrm{~m}$, is autogamous and can be classified into three groups according to its fruit color: yellow, red, and green (Aragão et al. 2010). The fruit color is controlled by two loci, $R$ and $G$; yellow coconuts present genotype rrgg, red coconuts $R-g g$ and green coconuts $r r G$ - (Bourdeix 1988).

There are several theories explaining the origin of Dwarf coconut; one of them establishes that it is a vari-

\footnotetext{
*Corresponding author, e-mail: telmasp2012@gmail.com DOI: $10.1508 /$ cytologia.82.167
}

ant of the Tall coconut that arose by mutation or inbreeding (Swaminathan and Nambiar 1961). However, the literature reports that both types are diploids with $2 n=2 x=32$ chromosomes (Sisunandar et al. 2010) with minor differences in karyotype (Raveendranath and Ninan 1973, Sisunandar and Adkins 2007). The arising of green Dwarf coconut in Brazil is also an issue under discussion; however, there are reports that it has been introduced from the Java Island in 1924, while the Tall coconut was introduced in 1553 from the Cape Verde Island (Fontes and Ferreira 2006).

Röser (1994) characterized specific regions of the DNA of various species of the Arecaceae family by banding (RON, CMA, DAPI). The Dwarf coconut chromosomal characterization is very incipient, hence the need to produce this information. Therefore, the aim of this work was the chromosomal characterization of the Brazilian green Dwarf coconut, describing the meiotic analysis, determining the conventional and differential karyotyping via CMA/DAPI banding of specific chromosomal regions and fluorescence in situ hybridization (FISH) using telomeric probes. 
Materials and methods

\section{Meiotic analysis}

The samples of plant material used in this study were obtained from 10 plants (seedlings) of the green Dwarf coconut group, which were kept in the field. Flower buds from different developmental stages were collected, fixed in a 3:1 solution (ethanol:acetic acid) and stored at $4^{\circ} \mathrm{C}$. The slides were prepared using the squash technique in an acetic carmine solution at $1 \%$ to verify the different stages of meiosis (Freitas et al. 2013). The recombination index (RI) was estimated according to Darlington (1958), verifying the number of chiasmata in ring and rod bivalents at diakinesis.

The normal (tetrads) and abnormal (polyads, triads, dyads and monads) post-meiotic products were counted to estimate the meiotic index (MI). Five slides were prepared and 300 cells of post-meiotic products were found per slide. The MI was calculated according to Love (1951).

Flower buds at pre-anthesis stage were collected at random and stored in $70 \%$ ethanol at $4^{\circ} \mathrm{C}$ for pollen viability. Five flower buds were used for genetic material to prepare the slides; their anthers were macerated to release the pollen grains in a triple solution of Alexander (1969).

The slides were analyzed under a bright field in an optic microscope Olympus BX60 and images were captured using a digital camera (3.3 MPixel Qcolor3C) connected to the microscope using the capture program Image-Pro Plus 5.1.

\section{Conventional and differential karyotyping Obtaining the metaphase plates}

Root tips of approximately $2 \mathrm{~cm}$ in length were collected from the Dwarf coconut seedlings, which were treated with paradichlorobenzene as an antimitotic solution for $10 \mathrm{~h}$ at $4^{\circ} \mathrm{C}$ to obtain the metaphases, according to Pereira et al. (2014).

The metaphase plates were obtained using the cell nuclei suspension protocol (Damasceno Jr. et al. 2009). Therefore, the root tips were separated by thickness and transferred to $1 \mathrm{~mL}$ eppendorf tubes and subjected to enzymatic digestion (pectinase 20\% and cellulase 2\%) at $37^{\circ} \mathrm{C}$. Subsequently, three centrifugations for $10 \mathrm{~min}$ at $5000 \mathrm{rpm}$ with distilled water for nuclei suspension were performed. Then, the nuclei were resuspended in a solution 2:1 (methanol:acetic acid) and stored in a freezer until the preparation of the slides. Approximately 50 plates were prepared in a humid chamber using $1 \mathrm{~mL}$ of the prepared material and dried at room temperature. After drying, different staining techniques were applied for obtaining the conventional and differential karyotyping or banding.

\section{Conventional karyotyping}

The slides were stained with $2 \%$ Giemsa solution for $15 \mathrm{~min}$ at $37^{\circ} \mathrm{C}$ for conventional karyotyping, and then covered with coverslips and analyzed in an optical microscope Olympus BX60 under a bright field through the immersion objectives at increases of 60 and $100 \times$.

Five metaphase-containing chromosomes with good condensation and scattering were captured among the hundreds of cells analyzed using the capture program Image-Pro Plus 5.1 (Media Cybernetics).

The chromosome absolute lengths and the long and short arm lengths were measured using the program Micro Measure 3.3 (Reeves 2001).

Based on these data, the ratio of arms ( $r=$ long arm/ short arm), the length of the haploid lot $(\mathrm{LHL}=$ sum of the absolute length of metaphase chromosomes) and the centromeric index $[\mathrm{CI}=$ (total length of short/long arm $) \times 100$ ] were estimated; the data were used for karyogram and ideogram constructions.

The karyotype asymmetry index was evaluated using the Total Form (TF) (Huziwara 1962). The chromosomes were classified according to Guerra (1986), who proposed four chromosomal types: metacentric (M, $\mathrm{r}=1.00$ to 1.49 ; $\mathrm{ic}=40.1$ to 50.0 ), submetacentric (SM, $\mathrm{r}=1,50$ to $2.99, \mathrm{ic}=25.1$ to 40.0$)$, acrocentric $(\mathrm{A}, \mathrm{r}=3.00$ to $7, \mathrm{ic}=0.01$ to 25.0$)$ and telocentric $(\mathrm{T}, \mathrm{r}=\infty, \mathrm{ic}=0)$. Homologous chromosomes were grouped according to their absolute size, centromere position and relationship between chromosome arms.

\section{CMA/DAPI banding and telomeric FISH}

The protocol proposed by Guerra and Souza (2002) was used for CMA/DAPI banding. Each slide was stained with a CMA drop, covered with a coverslip and maintained in a humid chamber for $1 \mathrm{~h}$ in the dark. Subsequently, the coverslip and the dye excess were removed with water and the slides were dried. Then, a drop of DAPI was added to the slides, which were maintained for $30 \mathrm{~min}$ in a humid chamber in the dark. The slides were prepared with the glycerol/McIlvaine medium.

The FISH protocol proposed by Souza et al. (2010) was used with modifications. The slides were subjected to treatment with $100 \mu \mathrm{gmL}^{-1}$ RNase in $2 \times \mathrm{SSC}$ buffer and incubated in a humid chamber for $1 \mathrm{~h}$ at $37^{\circ} \mathrm{C}$, followed by washing in $2 \times \mathrm{SSC}$ at room temperature and immersed in paraformaldehyde $4 \%$ for $10 \mathrm{~min}$ at room temperature. Then, another wash was performed in $2 \times \mathrm{SSC}$, and they were dehydrated in an alcoholic series of $70 \%$ and $96 \%$. The slides were air dried and the hybridization mixture was added to a final volume of $50 \%$ formamide, $10 \%$ dextran sulfate, $2 \times \mathrm{SSC}, 0.13 \% \mathrm{SDS}$ (sodiumdodecyl sulfate) and $66 \mathrm{ng}$ of the genomic probe obtained by PCR (5'-AAA TCC CAA ATC CCA AAT CCC AAA TCC CAA ATC CCAAAT CCC-3' and 5'-TTT AGGGTT TAGGGT TTA 
GGG TTT AGGGTT TAGCGT TTAGG-3') and marked through Nicktranslation following the manufacturer's protocol. The hybridization mixture was heated at $75^{\circ} \mathrm{C}$ for $10 \mathrm{~min}$. The cytological preparations containing the hybridization mixture were denatured at $75^{\circ} \mathrm{C}$ for $10 \mathrm{~min}$ and incubated overnight at $37^{\circ} \mathrm{C}$. The post-hybridization baths were performed at $42^{\circ} \mathrm{C}$ in $2 \times \mathrm{SSC}, 0.1 \times \mathrm{SSC}$ and again in $2 \times \mathrm{SSC}$. The telomeric probes were detected with digoxigenin-labeled in a BSA 5\% medium. The antibody excess was eliminated by washing in $4 \times$ SSC/0.2\% Tween 20. The slides were prepared and counterstained with DAPI/Vectashield ${ }^{\circledR}$ (M-1200) medium and stored at $6-8^{\circ} \mathrm{C}$ until analysis.

The slides stained with CMA/DAPI and FISH were analyzed using a fluorescence optical microscope Olympus $B X 60$ through the immersion objectives at increases of $60 \times$ and $100 \times$ with the $460 \mathrm{~nm}$ and $570 \mathrm{~nm}$ filters.

\section{Results and discussion}

\section{Meiotic analysis}

The meiosis was normal, with 16 chromosomes found in bivalent associations at the diakinesis phase (Fig. 1A), confirming that the species is diploid (Benassi et al. 2007, Sisunandar et al. 2010). Despite the normal meiosis (Fig. 1B, C), some abnormalities were observed during meiosis II, such as anaphases with problems in the fiber orientation (Fig. 1D). According to Shamina (2005), these spindle irregularities during meiosis II are important, since the spindles can unite or separate the homologous chromosomes. Tudor and Laude (1996), analyzing the meiosis in Dwarf and Tall coconuts, found univalents, laggard chromosomes and premature segregation of chromosomes; in the present work, none of these chromosomal abnormalities were observed.

The exchange (crossing-over) occurring during recombination not only creates new allele combinations, but in most organisms are essential to ensure proper segregation of homologous in the gametes (Martinez-Perez and Moore 2008). Therefore, to know the recombination rates of species and the type and number of chiasmata occurring is important, since this is a determining factor in the recombination frequency (Wijnker and de Jong 2008). The occurrence of rod and ring pairings was observed in Dwarf coconut (Fig. 1A). The rod pairing characterizes only one chiasma, while the ring type characterizes two chiasmata (Senda et al. 2005).

The estimated recombination rate for the Dwarf co-
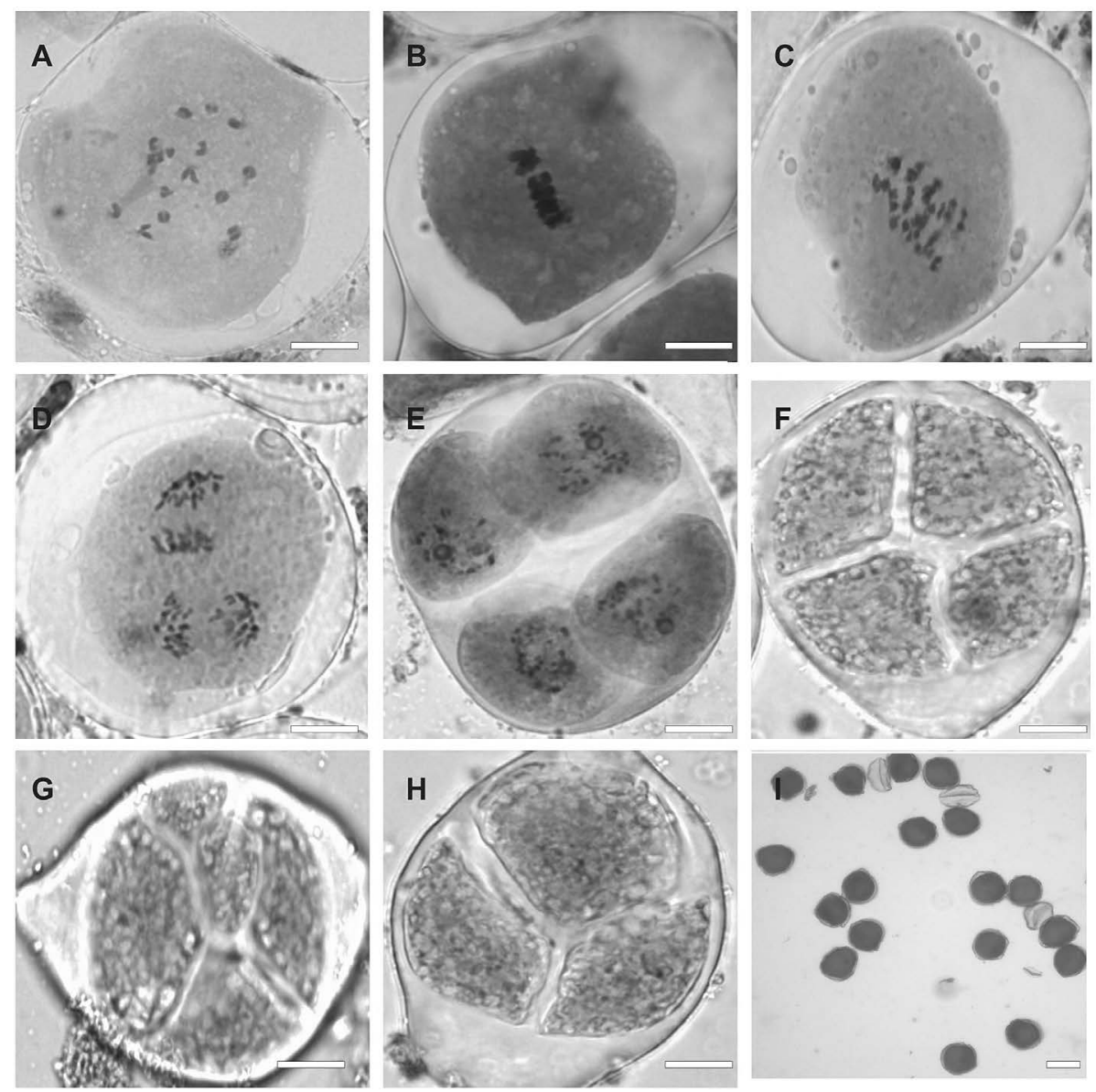

Fig. 1. Meiosis in Brazilian green Dwarf coconut. A-D) Meiosis I. A) Diakinesis where 16 bivalents can be observed, B) metaphase I, C) anaphase I, D) anaphase II where fiber disturbance can be observed. E-H) Post-meiotic products. E, F) Tetrads, G) abnormal tetrad, H) triad, I) viable pollen grains. 
conut was 17.04, which represents 1.06 chiasma per bivalent. Based on Forni-Martins and da Cruz (1996), the Dwarf coconut is a species that has a low frequency of chiasma per bivalent $(<1.5$ per bivalent). Crossovers occur preferentially in certain areas known as recombination hotspots, while areas with very low crossover occurrences are called recombination cold spots (Wijnker and de Jong 2008). For example, in corn, wheat and barley, recombination increases as it moves away from the centromere, and tomato and rice recombination tends to decrease as it approaches the telomeres (Mézard 2006). In coconut this kind of study was not done yet.

The green Dwarf coconut MI was $79 \%$, indicating a cytologically unstable material, since the stable genotypes have MI over 90\%; rates below this figure indicate that the plant may have difficulty generating progenies with a balanced chromosome number (Love 1951). However, the most frequent post-meiotic products found were the tetrads (Fig. 1E, F), which result from a normal meiosis. The meiotic index value may be explained by the irregularities found during meiosis, such as the converging anaphases which may result in irregular meiotic products with the presence of micronuclei (Fig. 1G), and triads (Fig. 1H) (Damasceno Jr. et al. 2010).

Pollen viability was $89.5 \%$, which may be considered as a good fertility (Fig. 1I). Plant fertility is connected to meiotic behavior (Defani-Scoarize et al. 1995), but neither the registered meiotic irregularities nor the IM below $90 \%$ had deleterious effects on the plant pollen viability. Tudor and Laude (1996) found in Dwarf coconut an average pollen viability of $94.8 \%$.

Based on the results, the Brazilian green Dwarf coconut has normal meiosis with bivalent pairing of chromosomes, confirming their diploid nature. Despite some meiotic irregularities, the pollen viability was good, indicating that these irregularities did not affect the fertility of genotypes.

\section{Conventional karyotyping}

Mitotic metaphase with good condensation and chromosome separation was observed according to Fig. 3A. All metaphases analyzed had 32 chromosomes (Fig. 2A), agreeing with the results of Sisunandar et al. (2010), which indicates that the species is diploid, that $x=n=16$, as confirmed by karyogram (Fig. 2B). The basic number of chromosomes found in the Arecaceae family apparently is $x=18$; however, other data have been reported, such as $x=17$ with large occurrence and also $x=13,14$ and 16 (Raven 1975). According to Röser (1994), the Arecaceae family has chromosome numbers varying from $2 n=26$ to $2 n=36$.

The Dwarf coconut chromosome length ranged from $5.57 \mu \mathrm{m}$ to $2.13 \mu \mathrm{m}$ (Table 1 ) with an average size of $3.65 \mu \mathrm{m}$, indicating that the species has a normal size of
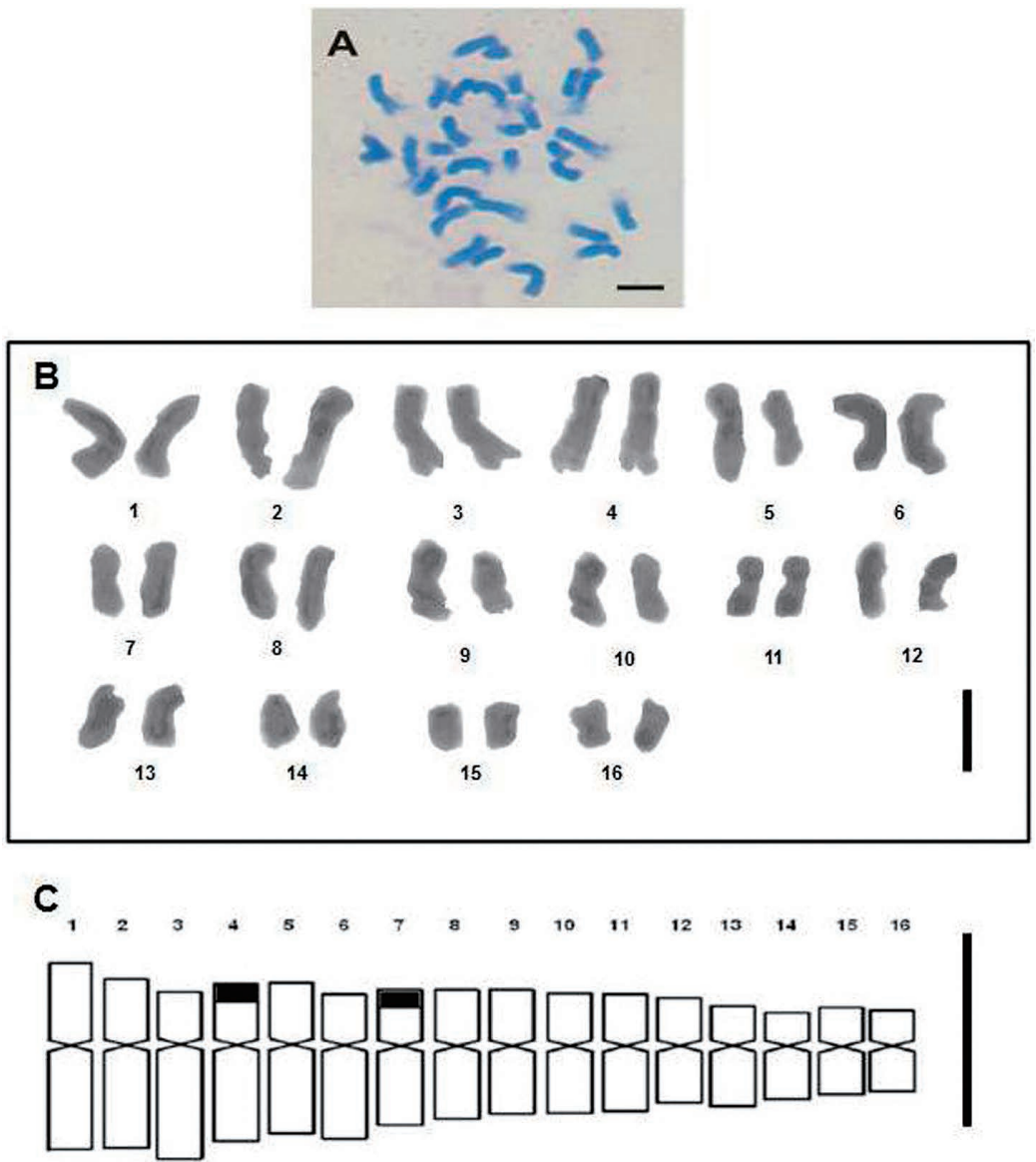

Fig. 2. Mitotic metaphase (A), karyogram (B) and idiogram of Brazilian green Dwarf coconut. Bar $=10 \mu \mathrm{m}$. 
chromosomes. Small chromosomes are those that have an average shorter than $3 \mu \mathrm{m}$, normal chromosomes have an average length ranging from $3 \mu \mathrm{m}$ to $8 \mu \mathrm{m}$, and large chromosomes have lengths greater than $8 \mu \mathrm{m}$ (Goicoechea and Giraldez 1996). Röser (1994) found chromosomal lengths varying from $6.0 \mu \mathrm{m}$ to $1.5 \mu \mathrm{m}$ in various palm trees species; Sisunandar et al. (2010), studying cryopreserved zygotic embryos of yellow Dwarf coconuts, found lengths ranging from $5.47 \mu \mathrm{m}$ to $2.03 \mu \mathrm{m}$, values close to those found in the present work. The differences in the results may be due to the condensation degree of chromosomes caused by the antimitotic agent (Sybenga 1959).

Five out of the 16 pairs of chromosomes assessed in this study were classified as submetacentric and 11 as metacentric (Fig. 2B); similar results were obtained by Sisunandar et al. (2010), although the five submetacentric pairs found in the present study were the 1,2, 3, 4,

Table 1. Mean length $(\mu \mathrm{m})$ and standard error of long (LA) and short arms (SA), chromosome (C), arm ratio (r), centromeric index (CI), and chromosome type (CT) in Brazilian green Dwarf coconut.

\begin{tabular}{|c|c|c|c|c|c|c|c|c|c|}
\hline & 1 & 2 & 3 & 4 & 5 & 6 & 7 & 8 & 9 \\
\hline LA & $3.52 \pm 0.03$ & $3.23 \pm 0.15$ & $3.09 \pm 0.10$ & $2.76 \pm 0.02$ & $2.59 \pm 0.03$ & $2.41 \pm 0.12$ & $2.27 \pm 0.12$ & $2.15 \pm 0.11$ & $2.04 \pm 0.10$ \\
\hline SA & $2.05 \pm 0.04$ & $1.68 \pm 0.04$ & $1.44 \pm 0.03$ & $1.65 \pm 0.02$ & $1.62 \pm 0.04$ & $1.56 \pm 0.02$ & $1.51 \pm 0.03$ & $1.50 \pm 0.09$ & $1.53 \pm 0.02$ \\
\hline $\mathrm{C}$ & $5.57 \pm 0.04$ & $4.91 \pm 0.03$ & $4.53 \pm 0.07$ & $4.41 \pm 0.05$ & $4.21 \pm 0.05$ & $3.97 \pm 0.02$ & $3.78 \pm 0.09$ & $3.65 \pm 0.04$ & $3.57 \pm 0.07$ \\
\hline $\mathrm{r}$ & 1.71 & 1.92 & 2.14 & 1.67 & 1.49 & 1.44 & 1.49 & 1.43 & 1.33 \\
\hline CI & 0.36 & 0.34 & 0.31 & 0.37 & 0.4 & 0.4 & 0.4 & 0.41 & 0.42 \\
\hline \multirow[t]{2}{*}{$\mathrm{CT}$} & SM & SM & SM & SM & M & M & M & M & M \\
\hline & 10 & 11 & 12 & 13 & 14 & 15 & 16 & LHL & \\
\hline LA & $1.97 \pm 0.01$ & $1.81 \pm 0.03$ & $1.73 \pm 0.09$ & $1.60 \pm 0.04$ & $1.49 \pm 0.05$ & $1.31 \pm 0.10$ & $1.31 \pm 0.03$ & & \\
\hline SA & $1.42 \pm 0.04$ & $1.46 \pm 0.05$ & $1.34 \pm 0.03$ & $1.33 \pm 0.04$ & $1.13 \pm 0.04$ & $1.04 \pm 0.11$ & $0.82 \pm 0.03$ & & \\
\hline $\mathrm{C}$ & $3.39 \pm 0.07$ & $3.27 \pm 0.03$ & $3.07 \pm 0.04$ & $2.93 \pm 0.05$ & $2.62 \pm 0.04$ & $2.35 \pm 0.10$ & $2.13 \pm 0.09$ & 58.36 & \\
\hline $\mathrm{r}$ & 1.38 & 1.23 & 1.29 & 1.20 & 1.31 & 1.25 & 1.59 & & \\
\hline CI & 0.41 & 0.44 & 0.43 & 0.45 & 0.43 & 0.44 & 0.38 & & \\
\hline $\mathrm{CT}$ & M & M & M & M & M & M & SM & & \\
\hline
\end{tabular}

$\mathrm{M}=$ Metacentric chromosome. $\mathrm{SM}=$ Submetacentric chromosome. $\mathrm{LHL}=$ Length of haploid lot.
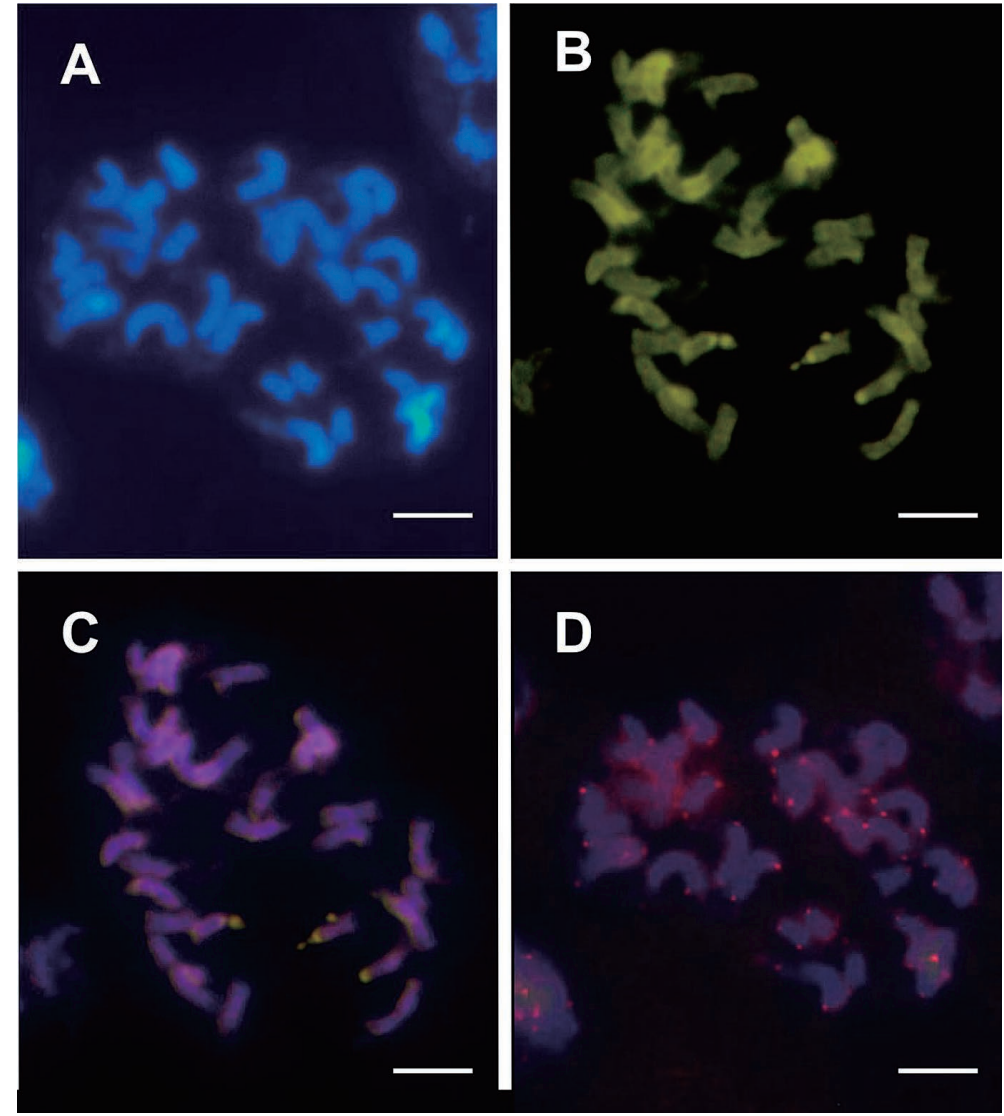

Fig. 3. Mitotic metaphase in Brazilian green Dwarf coconut. A) DAPI banding, B) CMA banding, C) CMA/DAPI banding, D) telomeric FISH. Bar $=10 \mu \mathrm{m}$. 
and 16, different from those found by those authors (3, 4, 5, 7 and 9). The difference in the classification of the chromosome type can be attributed to the antimitotic type used, the classification method, or the chromosomal rearrangements that may occur during the evolution of the species.

The metacentric and submetacentric chromosome types are the most common in the Arecaceae family (Röser 1994). However, other types have been found. Abreu et al. (2011), performing a karyological characterization of macauba (Acrocomia aculeata, Arecaceae), found 15 chromosome pairs, two of acrocentric type.

The length of the haploid lot (LHL) was $58.4 \mu \mathrm{m}$. The LHL allows inferring the approximated size of the genome of the species. Few studies characterize this index in the Arecaceae family. However, Corrêa et al. (2009) conducted a karyological review in five palm trees from the Butia genus, and observed LHL ranging from 32.2 to $37.8 \mu \mathrm{m}$. Oliveira (2011), studying three species from the genus Euterpe (Arecaceae), found LHL figures close to those obtained in the present study; Euterpe edulis species had LHL of $49.5 \mu \mathrm{m}$, Euterpe oleracea $51.3 \mu \mathrm{m}$ and Euterpe precatoria $59.4 \mu \mathrm{m}$. These data support the conclusion that the species $C$. nucifera is more similar to species from the genus Euterpe than the Butia regarding the length of the haploid lot.

The karyotypic asymmetry is a measure that indicates the chromosome length and centromere position variation, which are indicators of the karyotype evolution process (Schubert 2007). The green Dwarf coconut presented an asymmetrical karyotype with estimate TF of $39.5 \%$. The TF index (Total Form) can vary from 0 to $50 \%$; estimates over $45 \%$ are characteristic of highly symmetrical karyotypes (Huziwara 1962). Species with an asymmetric karyotype may be evolutionarily advanced (Maffei et al. 1996); however, Peruzzi and Eroglu (2013) reported that a symmetrical karyotype does not necessarily imply a primitive karyotype.

\section{CMA/DAPI bands}

After the double staining with the fluorochromes CMA and DAPI (Fig. 3B, C), heterochromatic blocks rich in visible terminal cytosine and guanine (CMA) in two chromosome pairs were found. These blocks were located on the short arm of the chromosome pairs 4 (submetacentric chromosomes) and 7 (metacentric chromosomes). These blocks were located exactly in the nucleolus organizing regions (NOR). NOR is the site of the repetitive sequence of DNA 45S (rDNA); during the chromosome mitotic contraction phase, the active RON at the interphase becomes visible as a constriction, called secondary constriction, which may be located at the terminal or interstitial region of the chromosome; when located in the interstitial position, it originates the satellite (Schubert 2007). The satellite lengths found were $1.36 \mu \mathrm{m}$ (chromosome 4) and $0.85 \mu \mathrm{m}$ (chromo- some 7).

Röser (1994) also examined the CMA/DAPI standard bands in various species of Arecaceae and pointed out that most species studied had CMA signs in only one chromosome pair, and that these signals were located in the subterminal region, where, as noted in the present study, the nucleolus organizing regions exist. In the genus Butia, the karyotypes of the studied species presented two chromosome pairs with satellites, a submetacentric and a metacentric pair (Corrêa et al. 2009). Oliveira (2011) also found two pairs of chromosomes with satellites in three species of the genus Euterpe (Arecaceae), with satellites identified in the subterminal region of the long arms of chromosomes. According to Röser (1994), satellites can be found in palm trees in the long arms, but are more commonly found in chromosome short arms.

Gaiero et al. (2012), using CMA/DAPI banding in chromosomes of the palm species Trithrinax campestris, observed CMA signals in four chromosome pairs, and different from many species of Arecaceae, these signals were located close to the centromere regions, non-coincident regions with the RON.

\section{Telomeric FISH}

The FISH with telomeric probe revealed marks only in the terminal regions of all chromosomes, although in some chromosomes, the marking had been more discrete (Fig. 3F). The telomeric sequences are typically short, highly repeated in tandem and are in the terminal regions of chromosomes, forming the telomeres (Sýkorová et al. 2003). Telomeres are essential sequences for the chromosome structure and function, and in plants, usually conserved sequences composed of (TTT AGGG) are detected in model plants (Arabidopsis thaliana, Nicotiana tabacum, Oryza sativa and Zea mays), except in tomato and Liliaceaes (Richards and Ausubel 1988, Sýkorová et al. 2003). Sýkorová et al. (2003) found a telomeric sequence similar to that found in human chromosomes telomeres (TTA GGG) in 16 species of 12 families of monocots.

The fact that the marking of the probes had concentrated on the chromosome terminal regions indicates that the Dwarf coconut had no structural arrangements during its evolution. According to Kolchinsky et al. (1994), telomeric probes hybridize to the terminal regions of chromosomes, but these probes can hybridize with other regions of the chromosome arms, indicating that the study material had translocations or inversions during the evolutionary process. This fact confirms that the palm tree evolution involved the reducing in chromosome number from the ancestral species $(2 n=36)$ via disploidy or aneuploidy (Röser 1994).

The discrete signals observed in some chromosomes may be due to reduction of telomeres during the plant development phase as observed in barley (cultivar 
Golden Promise), in which the telomeres varied in size depending on the embryo development, with length of $80 \mathrm{~kb}$ in young embryos and shorter (30 kb on average) in mature embryos (Kilian et al. 1995). According to Cowell et al. (2002), this reduction is common and varies during development, and is recovered from a somatic generation to the other, crossing a meiosis and embryo development period. During this period, the cells undergo abrupt changes in its methylation patterns of DNA and histone modifications relative to somatic cells (Cowell et al. 2002). An adjustment of the telomeres by the cell is also possible at that time. Alternative forms of telomere maintenance occur in plants through recombination and gene conversion, as reported in Arabidopsis (Riha et al. 2001).

\section{References}

Abreu, I. S., Carvalho, C. R., Carvalho, G. M. A. and Motoike, S. Y. 2011. First karyotype, DNA C-value and AT/GC base composition of macaw palm (Acrocomia aculeata, Arecaceae)-A promising plant for biodiesel production. Aust. J. Bot. 59: 149-155.

Alexander, M. P. 1969. Differential staining of aborted and nonaborted pollen. Stain Technol. 44: 117-122.

Aragão, W. M., Tupinamba, E. A., Angelo, P. C. S. and Ribeiro, F. E. 2010. Selection of coconut cultivars for different ecosystems of Brazil. In: Queiroz, M. A., Goedert, C. O. and Ramos, S. R. R. (eds.). Genetic Resources and Plant Breeding for Brazilian Northeast. Embrapa-SPI, Brasilia. pp. 1-24. (in Portuguese)

Benassi, A. C., Ruggiero, C., Martins, A. B. G. and Silva, J. A. A. 2007. Biometric characterization of coconut fruits (Cocos nucifera L.). Rev. Brs. Frutic. 29: 302-307. (in Portuguese)

Bourdeix, R. 1988. Genetic determinism in Dwarf coconut germ colour. Oléagineux 43: 373-374.

Corrêa, L. B., Barbieri, R. L., Rossato, M., Buttow, M. V. and Heiden, G. 2009. Karyological characterization of Butia (Arecaceae) palm trees. Rev. Bras. Frutic. 31: 1111-1116. (in Portuguese)

Cowell, I. G., Aucott, R., Mahadevaiah, S. K., Burgoyne, P. S., Huskisson, N., Bongiorni, S., Prantera, G., Fanti, L., Pimpinelli, S., Wu, R., Gilbert, D. M., Shi, W., Fundele, R., Morrison, H., Jeppesen, P. and Singh, P. B. 2002. Heterochromatin, HP1 and methylation at lysine 9 of histone $\mathrm{H} 3$ in animals. Chromosoma 111: $22-36$.

Damasceno Jr, P. C., Costa, F. R., Pereira, T. N. S., Freitas Neto, M. and Pereira, M. G. 2009. Karyotype determination in three Caricaceae species emphasizing the cultivated form (C. papaya L.). Caryologia 62: 10-15.

Damasceno Jr, P. C., Pereira, T. N. S., Freitas Neto, M. and Pereira, M. G. 2010. Meiotic behavior of Carica papaya and Vasconcellea monoica. Caryologia 63: 229-236.

Darlington, C. D. 1958. Evolution of Genetic Systems. Oliver and Boyd, London.

Defani-Scoarize, M. A., Pagliarini, M. S. and Aguiar, C. G. 1995. Evaluation of meiotic behavior in double-cross maize hybrids and their parents. Maydica 40: 319-324.

Fontes, H. R. and Ferreira, J. M. S. 2006. Coconut crop. Embrapa Technological Information, Brasilia. (in Portuguese)

Forni-Martins, E. R. and da Cruz, N. D. 1996. Recombination indices in species of Erythrina L. (Leguminosaea, Papilionoideae). Bot. J. Linn. Soc. 122: 163-170.

Freitas, L. L., Freitas Neto, M., Pereira, T. N. S. and Pereira, M. G. 2013. Meiotic behavior of male and hermaphrodite genotypes of papaya (Carica papaya L.). Cytologia 78: 163-171.
Gaiero, P., Mazzella, C., Vaio, M., Barros e Silva, A. E., Santiñaque, F. F., López-Carro, B., Folle, G. A. and Guerra, M. 2012. An unusually high heterochromatin content and large genome size in the palm tree Trithrinax campestris (Arecaceae). Aust. J. Bot. 60: $378-382$.

Goicoechea, P. G. and Giraldez, R. 1996. Plant Chromosome at Meiosis. In: Fukui, K. and Nakayama, S. (eds.). Plant Chromosomes: Laboratory Methods. CRC Press, Boca Raton. pp. 1-17.

Guerra, M. 1986. Reviewing the chromosome nomenclature of Levan et al. Rev. Bras. Genet. 9: 741-744.

Guerra, M. and Souza, M. J. 2002. How to observe chromosomes: A technique guide in plant, animal and human cytogenetics. FUNPEC-Editora, Ribeirão Preto. (in Portuguese)

Huziwara, Y. 1962. Karyotype analysis in some genera of Compositae. VIII. Further studies on the chromosomes of Aster. Am. J. Bot. 49: 116-119.

Kilian, A., Stiff, C. and Kleinhofs, A. 1995. Barley telomeres shorten during differentiation but grow in callus culture. Proc. Natl. Acad. Sci. U.S.A. 92: 9555-9559.

Kolchinsky, A., Funke, R. and Gresshoff, P. M. 1994. Dissecting molecular mechanisms of nodulation: taking a leaf from Arabidopsis. Plant Mol. Biol. 26: 549-552.

Love, R. M. 1951. Varietal differences in meiotic chromosome behavior of Brazilian wheats. Agron. J. 43: 72-76.

Maffei, E. M. D., Marin-Morales, M. A., Ruas, P. M. and Ruas, C. F. 1996. Analysis of karyotypical asymetry done in populations of Mikania micrantha HBK (Asteraceae). Barz. J. Gebnet. 19 Suppl.: 131-132. (in Portuguese)

Martinez-Perez, E. and Moore, G. 2008. To check or not to check? The application of meiotic studies to plant breeding. Curr. Opin. Plant Biol. 11: 222-227.

Mézard, C. 2006. Meiotic recombination hotspots in plants. Biochem. Soc. Trans. 34: 531-534.

Oliveira, L. C. 2011. Palinologya, cytogenetics, and nuclear DNA content in species from genus Euterpe. Master Thesis, UFLA, Lavras. (in Portuguese)

Pereira, T. N. S., Freitas Neto, M., Damasceno Jr, P. C., Rabelo, F. C. and Pereira, M. G. 2014. Genetic relationship between Vasconcellea and Carica based on their chromosome features. Cytologia 79: 567-573.

Peruzzi, L. and Eroglu, H. E. 2013. Karyotype asymmetry: again, how to measure and what to measure. Comp. Cytogenet. 7: 1-9.

Purseglove, J. W. 1972. Tropical Crops: Monocotyledons Vol. 1 \& 2. Longmans Ltd., London.

Raveendranath, T. G. and Ninan, C. A. 1973. A study of somatic chromosome complements of Tall and Dwarf coconuts (Cocos nucifera $\mathrm{L}$.) and its bearing on intervarietal variation and evolution of coconuts. J. Plant. Crops 1: 17-22.

Raven, P. H. 1975. The bases of angiosperm phylogeny: Cytology. Ann. Mo. Bot. Gard. 62: 724-764.

Reeves, A. 2001. Micro Measure: A new computer program for the collection and analysis of cytogenetic data. Genome 44: 439-443.

Richards, E. J. and Ausubel, F. M. 1988. Isolation of a higher eukaryotic telomere from Arabidopsis thaliana. Cell 53: 127-136.

Riha, K., McKnight, T. D., Griffing, L. R. and Shippen, D. E. 2001. Living with genome instability: Plant responses to telomere dysfunction. Science 291: 1797-1800.

Röser, M. 1994. Pathways of karyological differentiation in palms (Arecaceae). Plant Syst. Evol. 189: 83-122.

Schubert, I. 2007. Chromosome evolution. Curr. Opin. Plant Biol. 10: 109-115.

Senda, T., Hiraoka, Y. and Tominaga, T. 2005. Cytological affinities and interfertilities between Lolium temulentum and L. persicum (Poaceae) accessions. Hereditas 142: 45-50.

Shamina, N. V. 2005. A catalogue of abnormalities in the division 
spindles of higher plants. Cell Biol. Int. 29: 384-391.

Sisunandar and Adkins, S. W. 2007. Karyotype of some Indonesian coconut (Cocos nucifera L.) cultivars. Chromosome Res. 15: 73-37.

Sisunandar, R., Rival, A., Turquay, P., Samosir, Y. and Adkins, S. W. 2010. Cryopreservation of coconut (Cocos nucifera L.) zygotic embryos does not induce morphological, cytological or molecular changes in recovered seedlings. Planta 232: 435-447.

Souza, M. M., Urdampilleta, J. D. and Forni-Martins, E. R. 2010. Improvements in cytological preparations for fluorescent in situ hybridization in Passiflora. Genet. Mol. Res. 9: 2148-2155.

Swaminathan, M. S. and Nambiar, M. C. 1961. Cytology and origin of the Dwarf coconut palm. Nature 192: 85-86.

Sybenga, J. 1959. Some sources of error in the determination of chromosome length. Chromosoma 10: 355-364.

Sýkorová, E., Lim, K. Y., Kunická, Z., Chase, M. W., Bennett, M. D., Fajkus, J. and Leitch, A. R. 2003. Telomere variability in the monocotyledonous plant order Asparagales. Proc. Biol. Sci. 270: 1893-1904.

Tudor, M. A. and Laude, R. P. 1996. Cytogenetics of coconut (Cocos nucifera L.) varieties Catigan Green Dwarf (CAT) and Laguna Tall (Lag) and their $\mathrm{F}_{1}$ hybrid. Philipp. J. Crop Sci. 21: 8.

Wijnker, E. and de Jong, H. 2008. Managing meiotic recombination in plant breeding. Trends Plant Sci. 13: 640-646. 